\title{
Downregulation of nitric oxide by electroacupuncture against hypoxic-ischemic brain damage in rats via nuclear factor- $\kappa \mathbf{B} /$ neuronal nitric oxide synthase
}

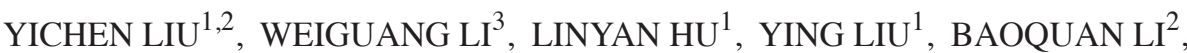 \\ CHANGQING SUN ${ }^{3}$, CHENGGANG ZHANG ${ }^{3}$ and LIPING ZOU ${ }^{1}$
}

\author{
${ }^{1}$ Department of Pediatrics, Chinese PLA General Hospital, Medical School of Chinese PLA, \\ Beijing 100853; ${ }^{2}$ Department of Pediatrics, 159th Hospital of Chinese People's Liberation Army, \\ Zhumadian, Henan 463000; ${ }^{3}$ Beijing Institute of Radiation Medicine, State Key Laboratory of Proteomics, \\ Cognitive and Mental Health Research Center of PLA, Beijing 100850, P.R. China
}

Received January 14, 2014; Accepted September 9, 2014

DOI: $10.3892 / \mathrm{mmr} .2014 .2879$

\begin{abstract}
The present study aimed to investigate the role of nitric oxide (NO) against perinatal hypoxic-ischemic brain damage (HIBD) in rats by electroacupuncture (EA) and to examine its potential neuroprotective mechanism. NO content, the number of positive cells, neuronal nitric oxide synthase (nNOS) and nuclear factor- $\kappa \mathrm{B}(\mathrm{NF}-\kappa \mathrm{B})$ in rat cortex cells were determined. The results demonstrated that treatment with EA significantly downregulated the NO content in the cortex cells $\left({ }^{*} \mathrm{P}<0.05,{ }^{* *} \mathrm{P}<0.01\right.$, compared with the control groups) and alleviated cell damage in the cortex of rats with HIBD. The activator, S-adenosyl-L-methionine and the inhibitor, hydroxylamine of cystathionine- $\beta$-synthase (CBS), aggravated and remitted the hypoxic damage in the cortex cells, respectively. In addition, treatment with EA significantly downregulated the expression of $n N O S$ and $N F-\kappa B$ in the rat cortex cells $\left({ }^{*} \mathrm{P}<0.05\right.$, ${ }^{* *} \mathrm{P}<0.01$, compared with the control groups). The results also indicated that treatment with EA downregulated the NO content of cortical cells against HIBD via the $N F-\kappa B / n N O S$ pathway and further implied that the hydrogen sulfide/CBS system may be involved in the process. The present study provided a significant reference for the prevention and treatment of HIBD using the EA technique and also described a novel protective mechanism.
\end{abstract}

Correspondence to: Professor Liping Zou, Department of Pediatrics, Chinese PLA General Hospital, Medical School of Chinese PLA, 28 Fuxing Road, Beijing 100853, P.R. China E-mail: zouliping21@hotmail.com

Key words: electroacupuncture, hypoxic-ischemic brain damage, nitric oxide, protection, nuclear factor- $\mathrm{\kappa} \mathrm{B} /$ neuronal nitric oxide synthase

\section{Introduction}

The emerging discipline of gaseous biology in traditional Chinese medicine, has attracted significant attention (1). Various gaseous signaling molecules, including hydrogen sulfide $\left(\mathrm{H}_{2} \mathrm{~S}\right)$ (2), carbon monoxide (3) and nitric oxide (NO) (4) are involved in regulating homeostasis during acupuncture, in which NO as a messenger has been well-documented under pathological and physiological conditions (5).

NO, also termed endothelium-derived relaxing factor (6), is one of the few gaseous signaling molecules known. NO is biosynthesized from L-arginine, oxygen and nicotinamide adenine dinucleotide phosphate by various nitric oxide synthase (NOS) enzymes in vivo (7), including neuronal NO synthase (nNOS), endothelial NO synthase and inducible NO synthase. NO can regulate various biological processes in vertebrates, including the regulation of blood flow (8), blood flow metabolism coupling (9), neurotransmission (10), memory formation (11) and the prevention of apoptosis in neurons (12). In particular, NO is involved in regulating hypoxic-ischemic brain damage (HIBD) (13). Excessive levels of NO can cause reperfusion injury by reacting with superoxide to produce the oxidant peroxynitrite (14), indicating that downregulating the content of NO in cortical cells may facilitate reperfusion injury recovery. Our previous study (15) demonstrated that HIBD upregulates the content of NO in rat cortical cells and that electroacupuncture (EA) can protect this damage by downregulating the NO content in cortical cells. However, the underlying mechanism remains to be elucidated. Therefore, the present study aimed to investigate the potential neuroprotective mechanism of $\mathrm{NO}$ downregulation by EA, including the NF- $\kappa \mathrm{B} / \mathrm{nNOS}$ pathway.

In addition, cystathionine- $\beta$-synthase (CBS) is a multi-domain enzyme, located mainly in the brain and nervous system $(16,17)$. It is able to catalyze the transsulfuration pathway to generate $\mathrm{H}_{2} \mathrm{~S} . \mathrm{H}_{2} \mathrm{~S}$ has various physiological effects, including cysteine S-sulfhydration $(18,19)$, preventing cytokine or oxidant-induced oxidative damage (20), inhibiting the expression of proinflammatory factors by downregulating 
the activation of NF- $\kappa \mathrm{B}(21)$ or upregulating the expression of heme oxygenase 1 (22). Therefore, in the present study it was hypothesized that the NF- $\kappa \mathrm{B} / \mathrm{nNOS}$ and $\mathrm{H}_{2} \mathrm{~S} / \mathrm{CBS}$ pathways crosstalk in the HIBD model. Consequently, the CBS activator, S-adenosyl-L-methionine (SAM) and the CBS inhibitor, hydroxylamine (HA) were used on the basis of the HIBD model.

\section{Materials and methods}

Animals and construction of the HIBD model. A total of 96 specific pathogen-free Sprague-Dawley rats (1 week-old, 12.9-21.0 g) were purchased and raised in the Laboratory Animal Center of the Academy of Military Medical Sciences (Beijing, China). The animals were housed at a temperature of $25 \pm 2^{\circ} \mathrm{C}$ with a $12 \mathrm{~h}$ light/dark cycle and were breast fed by their mothers. Each cage contained eight baby rats and their mother. The animals were randomly divided into eight groups $(n=12)$ : Sham, Sham + EA, HIBD, HIBD + EA, HIBD + SAM, $\mathrm{HIBD}+\mathrm{SAM}+\mathrm{EA}, \mathrm{HIBD}+\mathrm{HA}$ and HIBD + HA + EA. The rats were sacrificed using diethyl ether and the four limbs were fixed to enable incision along the neck midline. The left carotid artery communis was exposed through stripping of the thyroid, vein and nervous tissues, which was then ligated using 5/0 surgical line and sutured. After $2 \mathrm{~h}$, the rats were placed in a low-oxygen tank to maintain an appropriate environmental temperature under continuous hypoxia with $8 \%$ oxygen and $92 \%$ nitrogen for $2 \mathrm{~h}$. The Sham-operated groups were subjected to surgery, which also involved the exposure of the left carotid artery communis, however no ligation was performed. This experiment was approved by the Ethics Committee of the Chinese People's Liberation Army General Hospital (Beijing, China).

Intervention experiment of EA. The rats in the EA group were acupunctured at the BaiHui acupoint, which is the crossing point either side of the skull and linkline of the two ears and DaZhui acupoint, which lies below the detail of the cervical spine using EA $(\sim 0.25 \mathrm{~mm}$ in diameter and $10 \mathrm{~mm}$ in length, frequency, 2/100 Hz; intensity, $3 \mathrm{~mA}$ ) for a $30 \mathrm{~min}$ period for 14 days. The limbs of the rats in the control group were simultaneously fixed down, but EA was not performed. The rats in the HIBD + HA and HIBD + HA + EA groups were injected with $12.5 \mathrm{mg} / \mathrm{kg} / \mathrm{d}$ HA (Sigma-Aldrich, St. Louis, MO, USA), an inhibitor of CBS, via the peritoneal cavity $20 \mathrm{~min}$ prior to the acupuncture procedure or fixation. Similarly, the rats in the HIBD + SAM and the HIBD + SAM + EA groups were injected with $50 \mathrm{mg} / \mathrm{kg} / \mathrm{d}$ SAM (Sigma-Aldrich), an activator of CBS, via the peritoneal cavity $20 \mathrm{~min}$ prior to EA or fixation. The control group was injected with an equal volume of normal saline. Subsequently, six rats from each group were sacrificed by cervical dislocation and the brain cortex tissues were obtained to determine the NO content. Tissues from the remaining six animals in each group were perfused with 4\% paraformaldehyde for slicing and Nissl and immunohistochemistry (IHC) staining.

Determination of the NO content in the rat cortex cells. The brain cortex tissue $(\sim 50 \mathrm{mg})$ was homogenize in nine volumes $(\mathrm{w} / \mathrm{v}, \sim 0.5 \mathrm{ml})$ of $0.9 \%$ ice-cold sodium chloride.
The homogenate was centrifuged at 2,500 x $\mathrm{g}$ for $10 \mathrm{~min}$ and $200 \mu \mathrm{l}$ supernatant was obtained to measure the protein concentration. The absolute absorbance value $\left(\mathrm{A}_{550 \mathrm{~nm}}\right)$ was determined according to the manufacturer's instructions and the NO content was calculated using the following formula: $\mathrm{NO}=\left(\mathrm{A}_{\text {sample }}-\mathrm{A}_{\text {blank }}\right) /\left(\mathrm{A}_{\text {standard }}-\mathrm{A}_{\text {blank }}\right)$ x X x Y, where X represents the standard sample concentration $(\mu \mathrm{mol} / \mathrm{l})$ and $\mathrm{Y}$ represents the protein concentration $(\mathrm{g} / \mathrm{l})$. Column chart analysis was performed using Origin 9.0 software (OriginLab Co., Northampton, MA, USA). Each experiment was repeated at least three times.

Nissl staining. The slides (3-4 $\mu \mathrm{m})$ were deparaffinized and rehydrated, following which the frozen or vibratome sections were mounted onto the slides and rehydrated. The sections were partially over-stained with Nissl for $\sim 5 \mathrm{~min}$. The excess stain was removed with tap water, followed by $100 \%$ ethanol for $1 \mathrm{~min}$. The sections were transferred to dimethylbenzene (Changhai Chemical Factory, Beijing, China) for $1 \mathrm{~h}$ and differentiated with $95 \%$ ethanol. The sections were then dehydrated and mounted with neutral balsam. Images of the cortex were captured using a microscope connected to a CCD camera (magnification, x200; Olympus BX-41; Olypmus, Tokyo, Japan). Each experiment was repeated at least three times.

IHC assay. The slides (3-4 $\mu \mathrm{m})$ were deparaffinized, rehydrated, post-fixed with $4 \%$ paraformaldehyde for $10 \mathrm{~min}$ and then washed three times with $0.01 \mathrm{M}$ phosphate-buffered saline (PBS). Endogenous peroxidase was inactivated by incubating the sections in $3 \% \mathrm{H}_{2} \mathrm{O}_{2}$ for $30 \mathrm{~min}$. The sections underwent sequential incubations with $10 \%$ normal goat serum in $0.01 \mathrm{M}$ PBS for $30 \mathrm{~min}$ at room temperature. The sections were incubated in rabbit anti-nNOS (cat no. ZS-648; 1:100; Beijing Zhongshan, Golden Bridge Biotechnology Co., Ltd, Beijing, China) and rabbit anti-NF- $\mathrm{B}$ (cat no. ab1650; 1:400; Abcam, Cambridge, UK) antibodies in PBS containing $0.3 \%$ Triton $\mathrm{X}-100$ overnight at $4^{\circ} \mathrm{C}$. Following this, the sections were washed three times with PBS for 5 min each and then incubated in peroxidase-conjugated goat anti-rabbit IgG (1:200; Zymed, San Fransisco, CA, USA) for $1 \mathrm{~h}$ at room temperature. Subsequently, the sections were developed with diaminobenzidine (Sigma, St. Louis, MO, USA) in $0.1 \mathrm{M}$ tris-buffered saline containing $0.001 \% \mathrm{H}_{2} \mathrm{O}_{2}$ for $30-50 \mathrm{~min}$. Immunoreactions were observed under a microscope (Olympus, Tokyo, Japan). For image analysis, the IHC sections were captured using a microscope connected to a CCD camera (magnification, x200). Images of five specific areas in each region of the monitor were captured. The quantity of immunopositive cells and total positive area in the assigned subregions was measured using Image-Pro Plus 7.0 software (Media Cybernetics, Inc., Rockville, MD, USA) and column chart analysis was performed using Origin 9.0 software (OriginLab).

Statistical analysis. All data are expressed as the mean \pm standard deviation. Statistical analysis was performed using SPSS software (version 21.0; IBM, Armonk, NY, USA) and Student's t-test. $\mathrm{P}<0.05$ was considered to indicate a statistically significant difference. 


\section{Results}

Downregulation of $N O$ in the cortex of HIBD rats by EA. The NO content in the cortex of the Sham, Sham + EA, $\mathrm{HIBD}, \mathrm{HIBD}+\mathrm{EA}, \mathrm{HIBD}+\mathrm{SAM}, \mathrm{HIBD}+\mathrm{SAM}+\mathrm{EA}$, $\mathrm{HIBD}+\mathrm{HA}$ and HIBD + HA + EA groups was 2.3614 \pm 0.3807 , $1.4165 \pm 0.2592,3.5269 \pm 1.6970,1.6787 \pm 0.7213,5.5101 \pm 2.5914$, $2.6041 \pm 0.7773,2.8041 \pm 0.8377$ and $1.6784 \pm 0.7917$, respectively (Table I). HIBD significantly upregulated the NO content in the cortex cells compared with the Sham group. In addition, treatment with SAM further upregulated the NO content of the cortex cells in the HIBD rats compared with the Sham group. However, treatment with HA downregulated the NO content of the cortex cells compared with the Sham group. Furthermore, EA treatment downregulated the NO content in the Sham + EA, HIBD + EA, HIBD + SAM + EA and HIBD + HA + EA groups compared with those of the control groups, including Sham $\left({ }^{*} \mathrm{P}<0.05\right)$, HIBD $\left({ }^{* *} \mathrm{P}<0.01\right)$, HIBD + SAM $\left({ }^{* *} \mathrm{P}<0.01\right)$ and HIBD + HA $\left({ }^{*} \mathrm{P}<0.05\right)$, particularly in the HIBD and HIBD + SAM groups (Fig. 1).

Alleviation of cell damage in the cortex of the HIBD rats by $E A$. EA treatment alleviated the damage to the cortex in the HIBD rats and decreased the number of positive cells in the Sham + EA, HIBD + EA, HIBD + SAM + EA and HIBD + HA + EA groups compared with those of the control groups, including the Sham, HIBD, HIBD + SAM and HIBD + HA groups (Fig. 2). This result indicated that hypoxia triggered severe damage to the cortex cells, which was aggravated by the CBS activator SAM, but was alleviated by the CBS inhibitor HA (Fig. 2).

Downregulation of the expression of nNOS in the cortex cells of HIBD rats by EA. HIBD upregulated the expression of nNOS in the cortex cells compared with the Sham group and treatment with SAM significantly upregulated the expression of nNOS in the cortex cells of the HIBD rats compared with the Sham group. However, treatment with HA downregulated the expression of nNOS in the cortex cells compared with the Sham group. In addition, treatment with EA downregulated the expression of nNOS in the cortex cells of the HIBD rats compared with that of the control groups (Fig. 3A). The expression of nNOS was significantly downregulated following treatment with EA (Fig. 3B). A significant difference in the expression of nNOS was identified between the Sham + EA and the Sham groups (Fig. 3B; ${ }^{*} \mathrm{P}<0.05$ ). Similarly, a significant difference in the expression of nNOS was also identified between the other EA and the control groups, including HIBD (Fig. 3B; ${ }^{*} \mathrm{P}<0.05$ ), HIBD + SAM (Fig. 3B; ${ }^{*} \mathrm{P}<0.05$ ) and HIBD + HA (Fig. 3B; ${ }^{*} \mathrm{P}<0.01$ ).

Downregulation in the expression of $N F-\kappa B$ in the cortex cells of HIBD rats by EA. HIBD upregulated the expression of $\mathrm{NF}-\kappa \mathrm{B}$ in the cortex cells compared with the Sham group and treatment with SAM significantly upregulated the expression of NF- $\kappa \mathrm{B}$ in the cortex cells of HIBD rats compared with Sham treatment. However, treatment with $\mathrm{HA}$ downregulated the expression of $\mathrm{NF}-\kappa \mathrm{B}$ in the cortex cells of HIBD rats compared with the Sham group and treatment with EA downregulated the expression of $N F-\kappa B$ in
Table I. NO content assay in rat cortex cells.

\begin{tabular}{ll}
\hline $\begin{array}{l}\text { Data } \\
\text { Groups }\end{array}$ & $\begin{array}{c}\text { NO content } \\
(\text { mean } \pm \mathrm{SD} ; \\
\mathrm{n}=6 ; \mu \mathrm{mol} / \mathrm{g})\end{array}$ \\
\hline Sham & $2.3614 \pm 0.3807$ \\
Sham + EA & $1.4165 \pm 0.2592^{\mathrm{a}}$ \\
HIBD & $3.5269 \pm 1.6970$ \\
HIBD + EA & $1.6787 \pm 0.7213^{\mathrm{b}}$ \\
HIBD + SAM & $5.5101 \pm 2.5914$ \\
HIBD + SAM + EA & $2.6041 \pm 0.7773^{\mathrm{b}}$ \\
HIBD + HA & $2.8041 \pm 0.8377$ \\
HIBD + HA + EA & $1.6784 \pm 0.7917^{\mathrm{a}}$
\end{tabular}

${ }^{\mathrm{a}} \mathrm{P}<0.05,{ }^{\mathrm{b}} \mathrm{P}<0.01 . \mathrm{SD}$, standard deviation; NO, nitric oxide; EA, electroaccupuncture; HIBD, hypoxic-ischemia brain damage; SAM, S-adenosyl-L-methionine; HA, hydroxylamine.

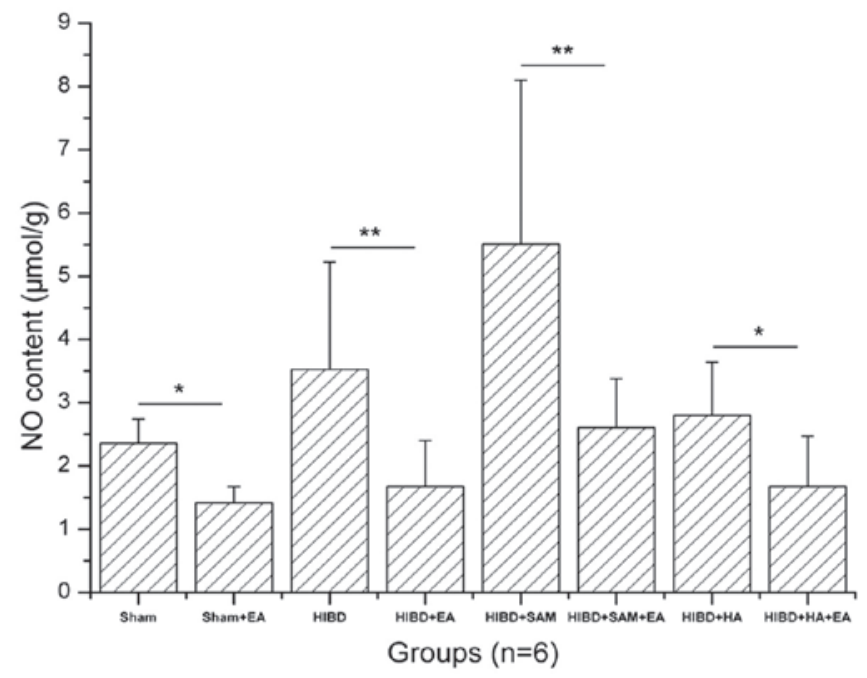

Figure 1. Column chart analysis of the NO content in cortex cells. The chart indicates that EA downregulates the NO content in the cortex cells, with a significant difference compared with each control $\left({ }^{*} \mathrm{P}<0.05,{ }^{* *} \mathrm{P}<0.01\right)$. NO, nitric oxide; EA, electroaccupuncture; HIBD, hypoxic-ischemia brain damage; SAM, S-adenosyl-L-methionine; HA, hydroxylamine.

the cortex cells compared with the control groups (Fig. 4A). A significant difference in the expression of $N F-\kappa B$ was observed between the Sham + EA and the Sham groups (Fig. 4B; $\left.{ }^{* *} \mathrm{P}<0.05\right)$. Similarly, a significant difference was identified in the expression of $\mathrm{NF}-\kappa \mathrm{B}$ between the other $\mathrm{EA}$ groups and the control groups, including HIBD (Fig. 4B; $\left.{ }^{* *} \mathrm{P}<0.01\right), \mathrm{HIBD}+\mathrm{SAM}$ (Fig. 4B; $\left.{ }^{*} \mathrm{P}<0.05\right)$ and HIBD + HA (Fig. 4B; $\left.{ }^{* *} \mathrm{P}<0.01\right)$.

\section{Discussion}

The present study demonstrated that treatment with EA can downregulate the NO content of cortical cells and alleviate cortex cell damage in HIBD rats. The number of positive cells significantly decreased following treatment with EA compared with each control. In addition, treatment with EA 


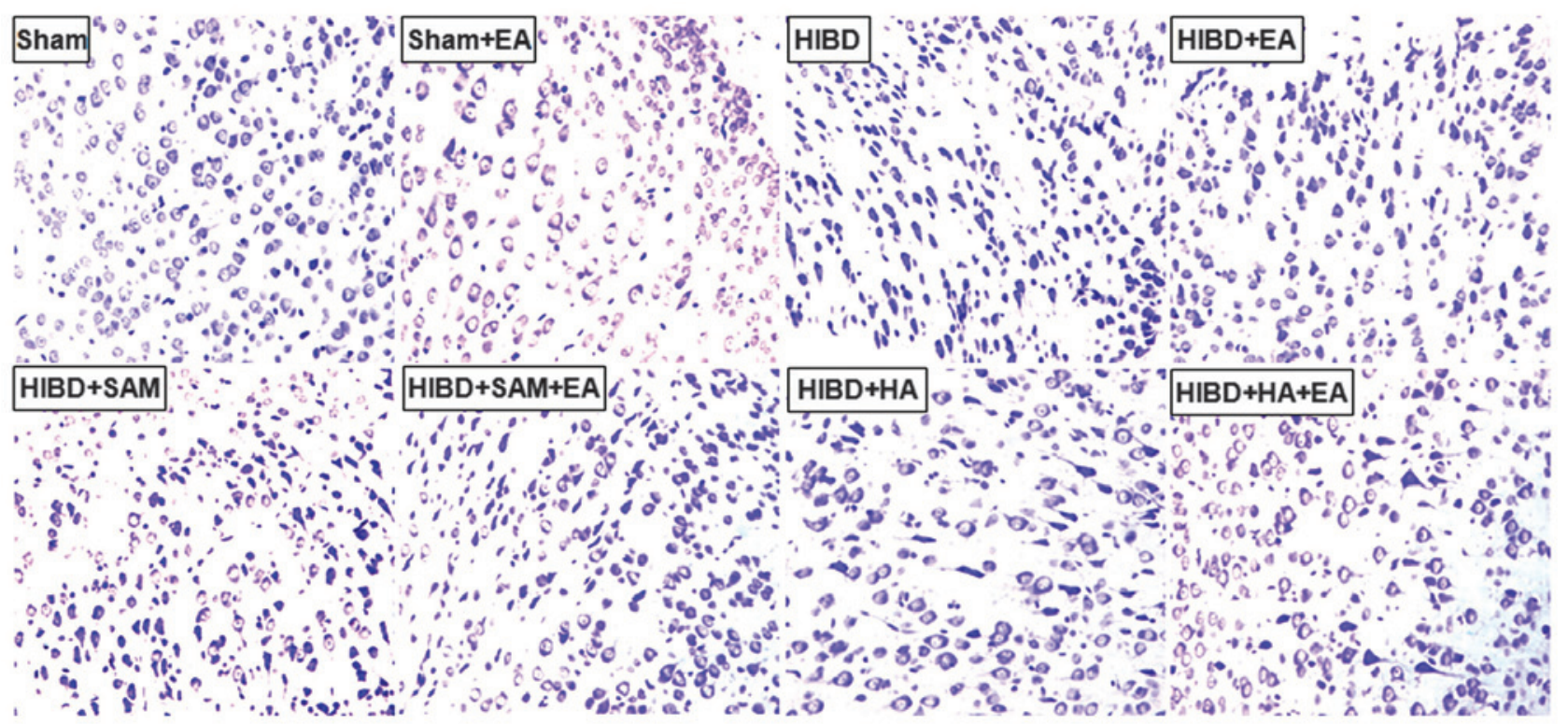

Figure 2. Morphological structure assay of the cortex by Nissl staining. The results indicated that EA is beneficial for alleviating cortex damage in perinatal HIBD rats. EA, electroacupuncture; HIBD, hypoxic-ischemia brain damage; SAM, S-adenosyl-L-methionine; HA, hydroxylamine.

A

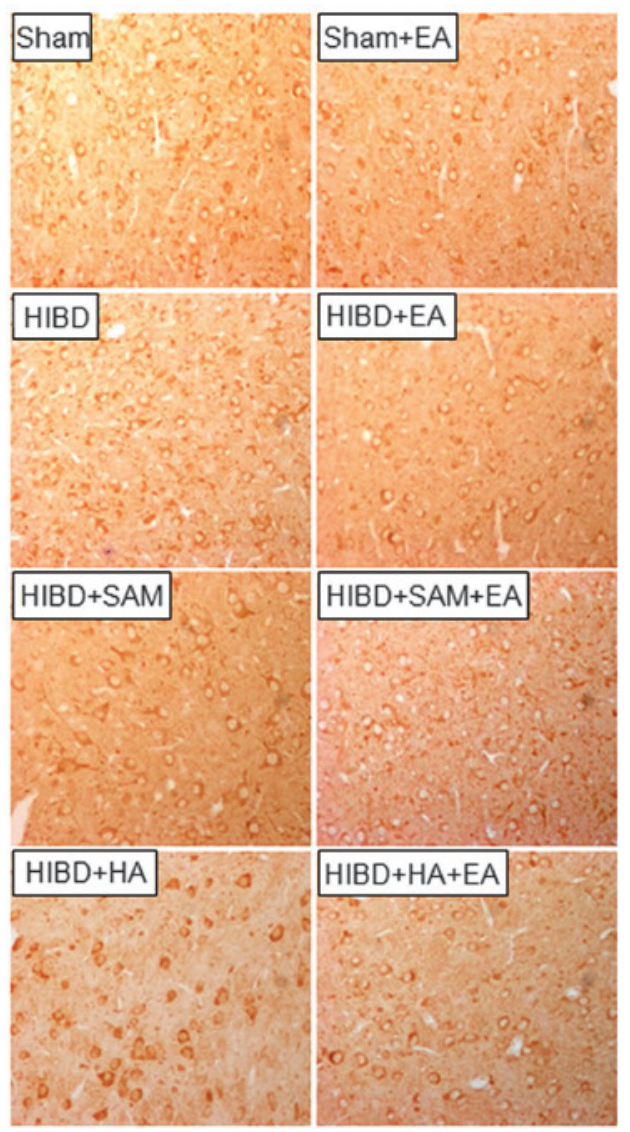

B

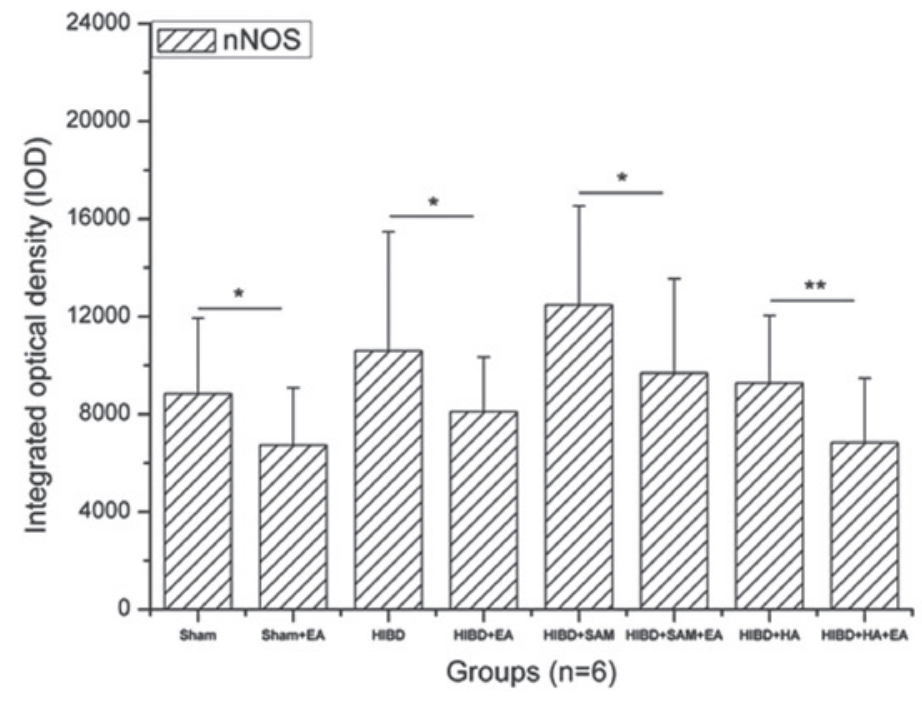

Figure 3. Assay of the level of nNOS expression in the cortex by IHC and column chart analysis. (A) IHC assay of the expression of nNOS in the cortex. (B) Column chart analysis of the expression of nNOS in the cortex. The results indicated that EA downregulates the expression of nNOS in the cortex, with a significant difference compared with each control ("P $\left.<0.05,{ }^{* *} \mathrm{P}<0.01\right)$. IHC, immunohistochemistry; nNOS, neuronal nitric oxide synthase; EA, electroacupuncture; HIBD, hypoxic-ischemia brain damage; SAM, S-adenosyl-L-methionine; HA, hydroxylamine.

downregulated the expression of nNOS and NF- $\mathrm{nB}$ in the rat cortex cells, whereas treatment with SAM significantly upregulated the expression of $n N O S$ and NF- $\kappa \mathrm{B}$ in the rat cortex cells. Treatment with HA significantly downregulated the expression of nNOS and NF- $\mathrm{kB}$ in the rat cortex cells. These results suggested that the NF- $\kappa B / n N O S$ and $\mathrm{H}_{2} \mathrm{~S} / \mathrm{CBS}$ 
A

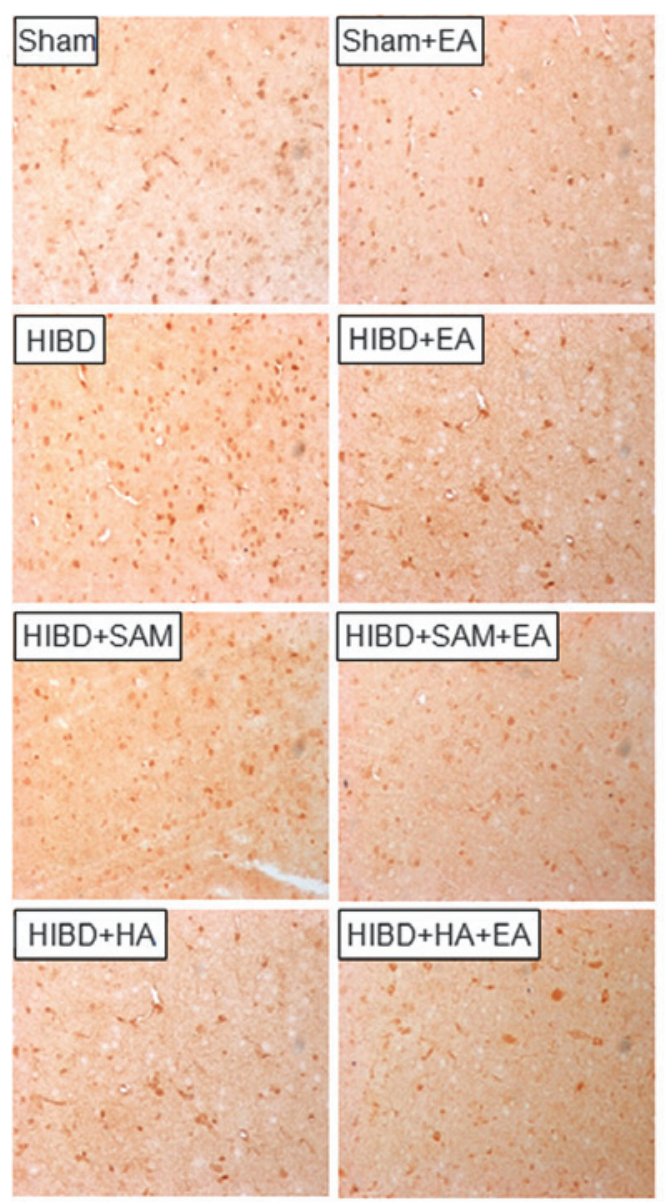

B

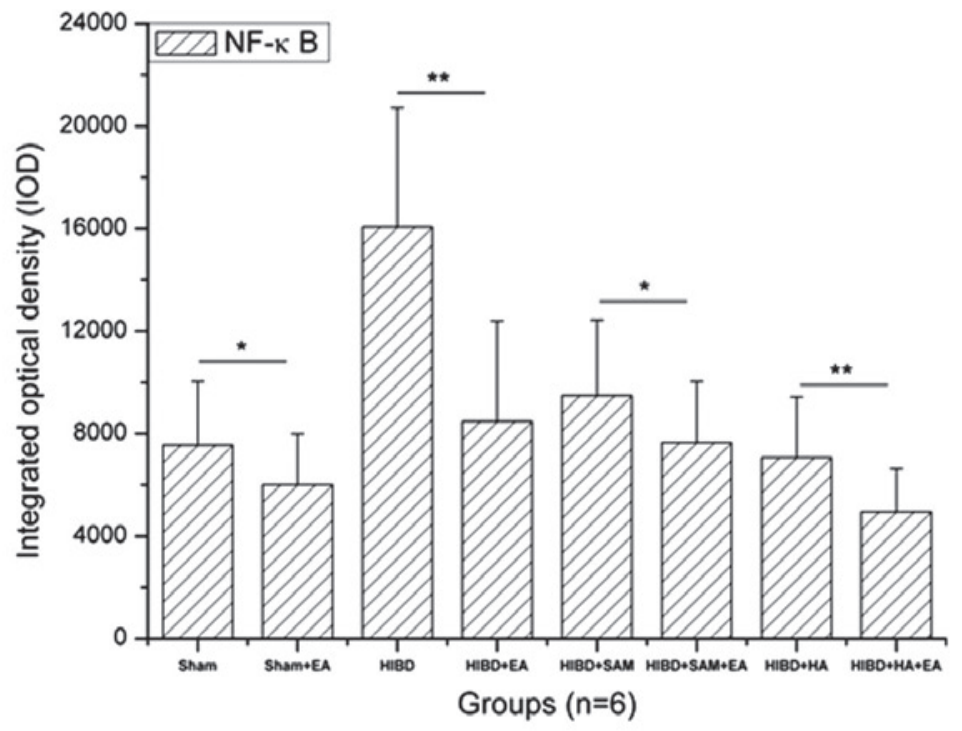

Figure 4. Assay of the expression level of NF- $\mathrm{B}$ in the cortex by IHC and column chart analysis. (A) IHC assay of the expression of NF- $\kappa \mathrm{B}$ in the cortex. (B) Column chart analysis of the expression of $\mathrm{NF}-\kappa \mathrm{B}$ in the cortex. The results indicated that EA downregulates the expression of NF- $\kappa \mathrm{B}$ in the cortex, with a significant difference compared with each control $\left({ }^{*} \mathrm{P}<0.05,{ }^{* *} \mathrm{P}<0.01\right)$. IHC, immunohistochemistry; NF- $\kappa \mathrm{B}$, nuclear factor- $\kappa \mathrm{B}$; EA, electroacupuncture; HIBD, hypoxic-ischemia brain damage; SAM, S-adenosyl-L-methionine; HA, hydroxylamine.

pathways may crosstalk during the recovery of HIBD-induced neuron damage.

There are two important mechanisms underlying the regulation of the biological function of NO, namely, S-nitrosation of thiols (23) and nitrosylation of transition metal ions (24). $\mathrm{S}$-nitrosation transfers thiol groups from the cysteine residues of proteins to form S-nitrosothiols and nitrosylation is able to transfer NO to a transition metal ion. Under physiological conditions, NO acts as a tonic inhibitory modulator to regulate carotid body chemosensory discharge by indirectly modifying vascular tone and oxygen delivery and/or directly modulating the excitability of the glomus cells and petrosal neurons (25). In addition, NO has a dual dose-dependent effect on carotid body chemosensory discharge (26).

Acupuncture is used as a curative tool in traditional Chinese medicine and is significantly neuroprotective in organisms through gaseous signaling molecules (27). Acupuncture increases the local generation of NO (4) and increases its content on the surface of the skin at acupoints (28). An increased level of $\mathrm{NO}$ has a curative effect on brain damage in rats (29), including transient middle cerebral artery occlusion and HIBD. Acupuncture is also able to cause a decrease in the nNOS/NO system to recover neuronal function, however, the underlying mechanism remains to be elucidated (15). In the present study, treatment with EA downregulated the NO content of the cortical cells in the Sham + EA group as well as following HIBD and treatment with SAM and HA. Treatment with EA also had a significant curative effect on HIBD-induced rat brain damage and downregulated the expression of nNOS and $\mathrm{NF}-\kappa \mathrm{B}$ in the rat brain. These results suggested that EA may cure brain damage by downregulating the $\mathrm{NF}-\kappa \mathrm{B} / \mathrm{nNOS}$ pathway and that this process is associated with the $\mathrm{H}_{2} \mathrm{~S} / \mathrm{CBS}$ pathway. However, the present study did not investigate the detailed regulatory association between the $\mathrm{NF}-\kappa \mathrm{B} / \mathrm{nNOS}$ and $\mathrm{H}_{2} \mathrm{~S} / \mathrm{CBS}$ pathways. Future studies are required to examine this regulatory effect.

In conclusion, the present study revealed that EA can alleviate HIBD in rats by downregulating the NO content of cortex cells. These results provide a significant reference for the prevention and treatment of HIBD using the EA technique and also describe a novel protective mechanism.

\section{Acknowledgements}

This study was sponsored and supported by the International Science and Technology Cooperation Foundation of the Ministry of Science and Technology of China (grant no. 2008DFA31850), the International Cooperation of Science and Technique Foundation of Beijing (grant no. 2007G05) and the Beijing Chinese Medicine Projects (grant no. JJ2005-17). 


\section{References}

1. Kajimura M, Nakanishi T, Takenouchi T et al: Gas biology: Tiny molecules controlling metabolic systems. Respir Physiol Neurobiol 184: 139-148, 2012.

2. Liu Y, Zou LP, Du JB and Wong V: Electro-acupuncture protects against hypoxic-ischemic brain-damaged immature rat via hydrogen sulfide as a possible mediator. Neurosci Lett 485: 74-78, 2010.

3. He J: Analysis on therapeutic effect of acupuncture combined with hyperbaric oxygenation on delayed encephalopathy in the patient of acute carbon monoxide poisoning. Zhongguo Zhen Jiu 28: 30-32, 2008 (In Chinese).

4. Ha Y, Kim M, Nah J, Suh M and Lee Y: Measurements of location-dependent nitric oxide levels on skin surface in relation to acupuncture point. Evid Based Complement Alternat Med 2012: 781460, 2012.

5. Ma SX, Li XY, Sakurai T and Pandjaitan M: Evidence of enhanced non-enzymatic generation of nitric oxide on the skin surface of acupuncture points: An innovative approach in humans. Nitric Oxide 17: 60-68, 2007.

6. Ignarro LJ, Buga GM, Wood KS, Byrns RE and Chaudhuri G: Endothelium-derived relaxing factor produced and released from artery and vein is nitric oxide. Proc Natl Acad Sci USA 84 9265-9269, 1987.

7. Palmer RM, Ashton DS and Moncada S: Vascular endothelial cells synthesize nitric oxide from 1-arginine. Nature 333: 664-666, 1988

8. Schmidl D, Boltz A, Kaya S, et al: Role of nitric oxide in optic nerve head blood flow regulation during isometric exercise in healthy humans. Invest Ophthalmol Vis Sci 54: 1964-1970, 2013.

9. Guarini G, Ohanyan VA, Kmetz JG et al: Disruption of trpv1-mediated coupling of coronary blood flow to cardiac metabolism in diabetic mice: Role of nitric oxide and bk channels Am J Physiol Heart Circ Physiol 303: H216-H223, 2012.

10. Phattanarudee S, Towiwat P, Maher TJ and Ally A: Effects of medullary administration of a nitric oxide precursor on cardiovascular responses and neurotransmission during static exercise following ischemic stroke. Can J Physiol Pharmacol 91: 510-520, 2013.

11. Ito E, Matsuo R and Okada R: Involvement of nitric oxide in memory formation in microbrains. Neurosci Lett 541: 1-3, 2013.

12. Martin LJ, Adams NA, Pan Y, Price A and Wong M: The mitochondrial permeability transition pore regulates nitric oxide-mediated apoptosis of neurons induced by target deprivation. J Neurosci 31: 359-370, 2011.

13. Tsuji M, Higuchi Y, Shiraishi K, Kume T, Akaike A and Hattori H: Protective effect of aminoguanidine on hypoxic-ischemic brain damage and temporal profile of brain nitric oxide in neonatal rat. Pediatr Res 47: 79-83, 2000.

14. Fabian RH, Perez-Polo JR and Kent TA: Perivascular nitric oxide and superoxide in neonatal cerebral hypoxia-ischemia. Am J Physiol Heart Circ Physiol 295: H1809-H1814, 2008.
15. Liu Y, Zou LP and Du JB: Nitric oxide-mediated neuronal functional recovery in hypoxic-ischemic brain damaged rats subjected to electrical stimulation. Brain Res 1383: 324-328, 2011.

16. Gong QH, Shi XR, Hong ZY, Pan LL, Liu XH and Zhu YZ: A new hope for neurodegeneration: Possible role of hydrogen sulfide. J Alzheimers Dis 24: 173-182, 2011.

17. Abe $\mathrm{K}$ and Kimura $\mathrm{H}$ : The possible role of hydrogen sulfide as an endogenous neuromodulator. J Neurosci 16: 1066-1071, 1996.

18. Edwards G, Félétou M and Weston AH: Hydrogen sulfide as an endothelium-derived hyperpolarizing factor in rodent mesenteric arteries. Circ Res 110: e13-e14, 2012.

19. Mustafa AK, Sikka G, Gazi SK, et al: Hydrogen sulfide as endothelium-derived hyperpolarizing factor sulfhydrates potassium channels. Circ Res 109: 1259-1268, 2012.

20. Liu C, Gu X and Zhu YZ: Synthesis and biological evaluation of novel leonurine-sprc conjugate as cardioprotective agents. Bioorg Med Chem Lett 20: 6942-6946, 2010.

21. Hu LF, Wong PT, Moore PK and Bian JS: Hydrogen sulfide attenuates lipopolysaccharide-induced inflammation by inhibition of p38 mitogen-activated protein kinase in microglia. J Neurochem 100: 1121-1128, 2007.

22. Kim KM, Pae HO, Zhung M, et al: Involvement of anti-inflammatory heme oxygenase- 1 in the inhibitory effect of curcumin on the expression of pro-inflammatory inducible nitric oxide synthase in raw264.7 macrophages. Biomed Pharmacother 62: 630-636, 2008

23. Yanagimoto T, Toyota T, Matsuki N, Makino Y, Uchiyama S and Ohwada T: Transnitrosation of thiols from aliphatic n-nitrosamines: S-nitrosation and indirect generation of nitric oxide. J Am Chem Soc 129: 736-737, 2007.

24. Kovacs I and Lindermayr C: Nitric oxide-based protein modification: Formation and site-specificity of protein s-nitrosylation. Front Plant Sci 4: 137, 2013.

25. Avolio A and Grassi G: Haemoglobin: Subtle scavenger of nitric oxide and modulator of retinal blood flow. J Hypertens 31 : 661-662, 2013.

26. Badn W and Siesjö P: The dual role of nitric oxide in glioma. Curr Pharm Des 16: 428-430, 2010.

27. Yang R, Huang ZN and Cheng JS: Anticonvulsion effect of acupuncture might be related to the decrease of neuronal and inducible nitric oxide synthases. Acupunct Electrother Res 25: $137-143,2000$.

28. Jou NT and Ma SX: Responses of nitric oxide-cgmp release in acupuncture point to electroacupuncture in human skin in vivo using dermal microdialysis. Microcirculation 16: 434-443, 2009.

29. Wang XY, Li XJ, Li DL, Wang CR and Guo XP: Progesterone exerts neuroprotective effect on hypoxic-ischemic encephalopathy-induced brain damage via inhibition expression of inducible nitric oxide synthase and nitric oxide production. Zhongguo Ying Yong Sheng Li Xue Za Zhi 28: 253-254, 262, 2012 (In Chinese) 